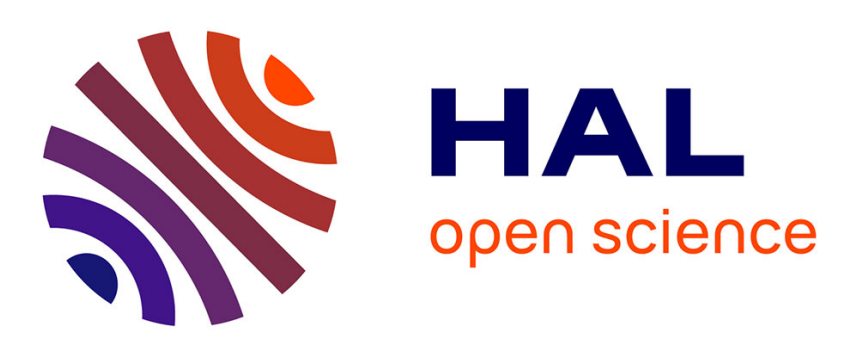

\title{
A framework for good biofilm reactor modeling practice (GBRMP)
}

B. E. Rittmann, J. P. Boltz, Doris Brockmann, G. T. Daigger, E. Morgenroth, K. H. Sorensen, I. Takacs, M. van Loosdrecht, P. A. Vanrolleghem

\section{- To cite this version:}

B. E. Rittmann, J. P. Boltz, Doris Brockmann, G. T. Daigger, E. Morgenroth, et al.. A framework for good biofilm reactor modeling practice (GBRMP). Water Science and Technology, 2018, 77 (5), pp.1149-1164. 10.2166/wst.2018.021 . hal-02628539

\section{HAL Id: hal-02628539 \\ https://hal.inrae.fr/hal-02628539}

Submitted on 26 May 2020

HAL is a multi-disciplinary open access archive for the deposit and dissemination of scientific research documents, whether they are published or not. The documents may come from teaching and research institutions in France or abroad, or from public or private research centers.
L'archive ouverte pluridisciplinaire HAL, est destinée au dépôt et à la diffusion de documents scientifiques de niveau recherche, publiés ou non, émanant des établissements d'enseignement et de recherche français ou étrangers, des laboratoires publics ou privés.

$$
\text { Copyright }
$$




\section{A framework for good biofilm reactor modeling practice (GBRMP)}

Article in Water Science \& Technology · January 2018

DOI: 10.2166/wst.2018.021

CITATION

1

9 authors, including:

Bruce Rittmann

Arizona State University

714 PUBLICATIONS 24,715 CITATIONS

SEE PROFILE

Doris Brockmann

INRA Transfert

42 PUBLICATIONS 417 CITATIONS

SEE PROFILE
Joshua Boltz

Volkert, Inc.

76 PUBLICATIONS $\mathbf{4 8 4}$ CITATIONS

SEE PROFILE

Glen T Daigger

University of Michigan

285 PUBLICATIONS 4,799 CITATIONS

SEE PROFILE

Some of the authors of this publication are also working on these related projects:

Production of valuable chemicals by anaerobic bacteria in an syngas-based Membrane Biofilm Reactor View project

Biogrout, ground improvement by microbially induced carbonate precipitation View project 


\title{
A framework for good biofilm reactor modeling practice (GBRMP)
}

\author{
Bruce E. Rittmann, Joshua P. Boltz, Doris Brockmann, Glen T. Daigger, \\ Eberhard Morgenroth, Kim Helleshøj Sørensen, Imre Takács, \\ Mark van Loosdrecht and Peter A. Vanrolleghem
}

\section{ABSTRACT}

A researcher or practitioner can employ a biofilm model to gain insight into what controls the performance of a biofilm process and for optimizing its performance. While a wide range of biofilmmodeling platforms are available, a good strategy is to choose the simplest model that includes sufficient components and processes to address the modeling goal. In most cases, a onedimensional biofilm model provides the best balance, and good choices can range from handcalculation analytical solutions, simple spreadsheets, and numerical-method platforms. What is missing today is clear guidance on how to apply a biofilm model to obtain accurate and meaningful results. Here, we present a 5-step framework for Good Biofilm Reactor Modeling Practice (GBRMP). The first four steps are (1) obtain information on the biofilm reactor system, (2) characterize the influent, (3) choose the plant and biofilm model, and (4) define the conversion processes. Each step demands that the model user understands the important components and processes in the system, one of the main benefits of doing biofilm modeling. The fifth and sixth steps are to calibrate and validate the model: System-specific model parameters are adjusted within reasonable ranges so that model outputs match actual system performance. Calibration is not a simple 'by the numbers' process, and it requires that the modeler follows a logical hierarchy of steps. Calibration requires that the adjusted parameters remain within realistic ranges and that the calibration process be carried out in an iterative manner. Once each of steps 1 through 5 is completed satisfactorily, the calibrated model can be used for its intended purpose, such as optimizing performance, trouble-shooting poor performance, or gaining deeper understanding of what controls process performance.

Key words | biofilm, framework, good practice, modeling, reactor

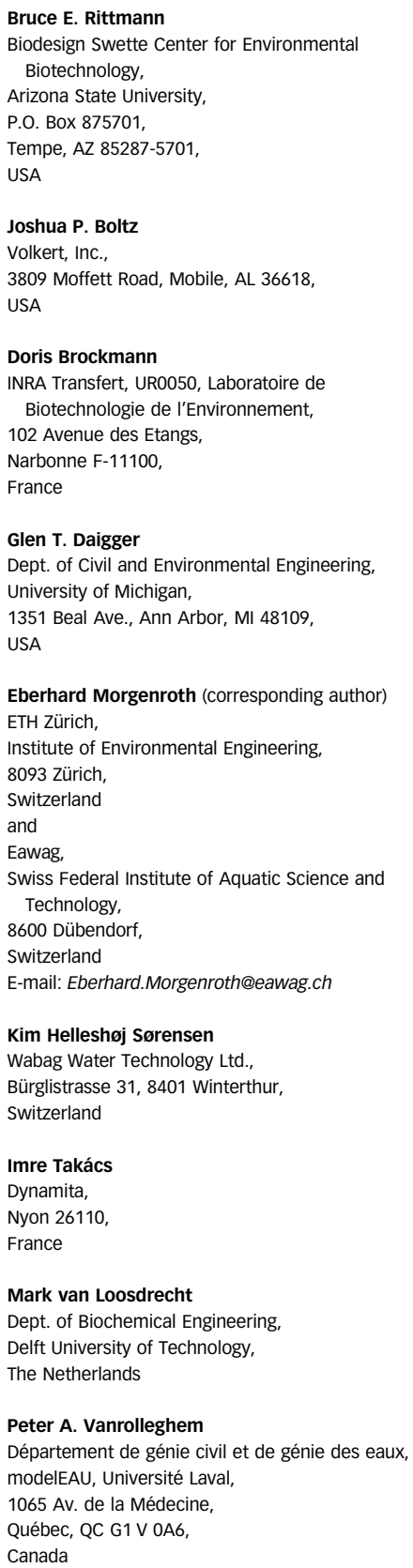

Eberhard Morgenroth (corresponding author) ETH Zürich,

Institute of Environmental Engineering, 8093 Zürich,

Switzerland and

Eawag,

Swiss Federal Institute of Aquatic Science and Technology,

8600 Dübendorf,

Switzerland

E-mail: Eberhard.Morgenroth@eawag.ch

Kim Helleshøj Sørensen

Wabag Water Technology Ltd.

Bürglistrasse 31, 8401 Winterthur,

Switzerland

Imre Takács

Dynamita,

Nyon 26110

France

Mark van Loosdrecht Dept. of Biochemical Engineering,

Delft University of Technology,

The Netherlands

Peter A. Vanrolleghem

Département de génie civil et de génie des eaux, modelEAU, Université Laval,

1065 Av. de la Médecine

Québec, QC G1 V OA6,

Canada 


\section{NOTATION}

\begin{tabular}{|c|c|c|}
\hline $\begin{array}{l}\text { Symbol/ } \\
\text { Abbreviation }\end{array}$ & Definition & Dimensions $^{\mathbf{a}}$ \\
\hline$A_{F}$ & Biofilm surface area & $\mathrm{L}^{2}$ \\
\hline BAF & Biological aerated filter & \\
\hline $\mathrm{D}$ & Substrate diffusion coefficient in the bulk liquid & $\mathrm{L}^{2} \mathrm{~T}^{-1}$ \\
\hline $\mathrm{D}_{\mathrm{F}}$ & Substrate diffusion coefficient in the biofilm & $\mathrm{L}^{2} \mathrm{~T}^{-1}$ \\
\hline DO & Dissolved oxygen & $\mathrm{ML}^{-3}$ \\
\hline IFAS & Integrated fixed-film activated sludge & \\
\hline $\mathrm{J}_{\mathrm{F}}$ & Substrate flux into the biofilm and from the bulk liquid & $\mathrm{M} \mathrm{L}^{-2} \mathrm{~T}^{-1}$ \\
\hline K & Half-maximum-rate concentration & $\mathrm{M} \mathrm{L}^{-3}$ \\
\hline $\mathrm{k}_{\text {attach }}$ & Rate coefficient for attachment from the bulk to the biofilm & Variable $^{b}$ \\
\hline $\mathrm{k}_{\text {detatch }}$ & Rate coefficient for detachment from the biofilm to the bulk & Variable $^{b}$ \\
\hline $\mathrm{k}_{\mathrm{L}} \mathrm{a}$ & Gas-liquid transfer coefficient & $\mathrm{T}^{-1}$ \\
\hline $\mathrm{L}_{\mathrm{F}}$ & Biofilm thickness & $\mathrm{L}$ \\
\hline $\mathrm{L}_{\mathrm{L}}$ & Mass transfer boundary layer thickness & $\mathrm{L}$ \\
\hline MBBR & Moving bed biofilm reactor & \\
\hline MBfR & Membrane attached biofilm reactor & \\
\hline$\hat{q}$ & Maximum specific rate of substrate utilization & $\mathrm{M}_{\text {substrate }} \mathrm{M}_{\text {biomass }}^{-1} \mathrm{~T}^{-1}$ \\
\hline $\mathrm{RBC}$ & Rotating biological contactor & \\
\hline S & $\begin{array}{l}\text { Substrate concentration in the bulk liquid where substrate is a generic term that can relate to any } \\
\text { of the rate limiting compounds such as organic substrate, } \mathrm{NH}_{4}^{+}, \mathrm{NO}_{3}^{-}, \text {or } \mathrm{O}_{2} \text {. }\end{array}$ & $\mathrm{M}_{\text {substrate }} \mathrm{L}^{-3}$ \\
\hline $\mathrm{S}_{\mathrm{B}}$ & Soluble (readily) biodegradable organic substrate & $\mathrm{M}_{\text {substrate }} \mathrm{L}^{-3}$ \\
\hline$S_{\mathrm{F}}$ & Substrate concentration inside the biofilm & $\mathrm{M}_{\text {substrate }} \mathrm{L}^{-3}$ \\
\hline $\mathrm{S}_{\mathrm{LF}}$ & Substrate concentration at the outer surface of the biofilm & $\mathrm{M}_{\text {substrate }} \mathrm{L}^{-3}$ \\
\hline SOTE & Standard oxygen transfer efficiency & - \\
\hline TSS & Total suspended solids & $M_{\text {solids }} L^{-3}$ \\
\hline UASB & Upflow anaerobic sludge blanket & \\
\hline VSS & Volatile suspended solids & $\mathrm{M}_{\text {solids }} \mathrm{L}^{-3}$ \\
\hline $\mathrm{X}_{\mathrm{F}}$ & $\begin{array}{l}\text { State variable that quantifies particulate components in a biofilm (biomass per unit biofilm } \\
\text { volume). Most biofilm models and simulators consider different types such as heterotrophic } \\
\text { biomass }\left(\mathrm{X}_{\mathrm{OHO}, \mathrm{F}}\right) \text {, autotrophic nitrifying biomass }\left(\mathrm{X}_{\mathrm{ANO}, \mathrm{F}} \text { ), and unbiodegradable particulate }\right. \\
\text { biomass }\left(\mathrm{X}_{\mathrm{U}, \mathrm{F}} \text { ). The sum of these particulate components corresponds to the overall measured }\right. \\
\mathrm{X}_{\text {Tot,F. Note that the value of the different } \mathrm{X}_{\mathrm{F}} \text { may be constant (as is assumed in Equation (1)) or }} \\
\text { may vary over the biofilm thickness (Wanner et al. 2006). }\end{array}$ & $\mathrm{M}_{\text {solids }} \mathrm{L}^{-3 \mathrm{c}}$ \\
\hline $\mathrm{X}_{\mathrm{Tot}, \mathrm{A}}$ & Amount of biomass in the biofilm per unit substratum area (Note: $\left.\mathrm{X}_{\mathrm{Tot}, \mathrm{A}}=\mathrm{X}_{\mathrm{Tot}, \mathrm{F}} \cdot \mathrm{L}_{\mathrm{F}}\right)$ & $\mathrm{M}_{\text {solids }} \mathrm{L}^{-2}$ \\
\hline $\mathrm{X}_{\mathrm{Tot}, \mathrm{F}}$ & $\begin{array}{l}\text { Concentration of biomass in the biofilm (biomass per unit biofilm volume) where biomass is } \\
\text { typically quantified as VSS, TSS, or COD. In other references } \mathrm{X}_{\mathrm{Tot}, \mathrm{F}} \text { is sometimes referred to as } \\
\text { biofilm biomass density of biofilm biomass concentration. (Note: } \mathrm{X}_{\mathrm{Tot}, \mathrm{F}}=\mathrm{X}_{\mathrm{Tot}, \mathrm{A}} / \mathrm{L}_{\mathrm{F}} \text { ) }\end{array}$ & $\mathrm{M}_{\text {solids }} \mathrm{L}^{-3 \mathrm{c}}$ \\
\hline $\mathrm{X}_{\mathrm{U}}$ & Particulate unbiodegradable organic matter concentration & $\mathrm{M}_{\text {solids }} \mathrm{L}^{-3}$ \\
\hline $\mathrm{z}$ & Distance dimension perpendicular to the biofilm surface & $\mathrm{L}$ \\
\hline$\alpha$ & oxygen transfer efficiency & - \\
\hline
\end{tabular}

aDimensions are defined according to the SI base quantities L for length, M for mass, T for time. Nomenclature is based on Wanner et al. (2006) and Corominas et al. (2010). ${ }^{b}$ Depends on the type of rate expressions used (e.g., Table 17.4 in Morgenroth 2008).

${ }^{c}$ Concentrations in the biofilm are per unit volume biofilm and not per overall reactor volume. For simple (planar) biofilm geometries the definition of the biofilm volume is straightforward. For heterogeneous structures the unit biofilm volume considers only the space occupied by particulate components and not the pore space. See also corresponding discussion related to Figure 2.2(c) in Wanner et al. (2006). 


\section{INTRODUCTION}

It would not be an exaggeration to say that development and adoption of the International Water Association (IWA) Activated Sludge Models (ASMs), along with their incorporation into plant-wide modeling protocols, has transformed wastewater-treatment education, research, and practice (Daigger 20II). Since their introduction (Henze et al. 1987), these models have become the accepted means for evaluating, designing, and assisting with the operation of water resources recovery facilities (WRRFs) using the activated sludge process in its many variations. This occurs because the models and associated protocols meet the criteria for useful application. First, they are based on a combination of sound science and engineering, but are scalable to provide the level of detail necessary to address real-world challenges. Second, the models have kept the complexity as low as possible while encompassing truly important components and processes. Third, a strong experience base has accumulated to allow their reliable application. Finally, their widespread application provides a common understanding and language that facilitate communication between researchers and practitioners, beginning with the instruction of students learning about biological water resources recovery.

Why do we use models of biological processes? First and foremost, models are efficient means to incorporate known and relevant science, engineering, and practice into an executable tool. On the one hand, the results of their proper application can be relied upon for their generalizable accuracy, in comparison to empirical design criteria, which are site and situation specific. On the other hand, model failures in specific applications identify areas needing further research. In this way, the routine and consistent application of accepted models drives the improvement of fundamental understanding and practice.

Models with firm mechanistic and experiential bases can be used reliably to establish design and operating criteria for WRRFs, resulting in more efficient and effective operation. They also can be used for troubleshooting, i.e., identifying the reasons for operating difficulties and necessary corrective actions. Likewise, models can be used to determine the operating limits for existing facilities, along with methods to optimize and further increase capacity and performance.

While the ASMs provide these kinds of tools for WRRFs based on suspended-growth processes, biofilm-based processes do not have analogous well-established linkages to biofilm models. This deficiency cannot be fixed by applying
ASMs to biofilm processes, because of the profound importance of mass-transport processes in biofilms, along with process kinetics (Boltz \& Daigger 2010).

While a plethora of biofilm models exist (Wanner et al. 2006), no consistent and widely used protocol is available to guide the use of biofilm models to design and operate biofilm reactors. This lack of agreed-upon methodology for using biofilm models has been a barrier to the implementation of biofilm reactors in WRRFs.

What if an agreed-upon means to use biofilm models were in place? Examples of the practical questions that could be addressed by a biofilm model include: (1) What is the achievable flux of $\mathrm{NH}_{4}^{+}-\mathrm{N}$, thereby allowing the required size of the biofilm reactor to achieve a specified effluent concentration to be determined? (2) Why is my biofilm reactor not performing as well as needed (e.g., insufficient five-day biochemical oxygen demand, $\mathrm{BOD}_{5}$, removal or the production of $\mathrm{NO}_{2}^{-}-\mathrm{N}$ )? (3) Why does process performance vary from summer to winter, and what can I do about it? (4) What is the biofilm carrier requirement and associated reactor size for the different types of biofilm reactors I am considering? (5) How do biofilmcarrier features affect important biofilm characteristics, such as surface area, detachment rate, and biomass accumulation? It is easy to see the practical value of a reliable and robust protocol for modeling biofilm reactors.

In this paper, we present a Framework for Good Biofilm Reactor Modeling Practice (GBRMP). We first provide a succinct overview of available biofilm models; we conclude that one-dimension (1-D) models generally are sufficient for engineering practice. We then outline a five-step GBRMP Framework. It is structured along the lines of the widely used Good Modeling Practices Framework for Activated Sludge (Rieger et al. 20I3), but with essential differences related to biofilm reactors.

Based on the GBRMP Framework, we provide guidance for selecting the appropriate one-dimensional (1D) biofilm model, and we follow up with simple examples of applying the Framework. We conclude with a discussion of the need for model calibration when modeling biofilm reactors.

\section{AN OVERVIEW OF BIOFILM MODELS}

Biofilm modeling began in the mid-1970s with the seminal works of Atkinson \& Davies (1974), Atkinson \& Davies (1974), Williamson \& McCarty (1976), and Harremoes (1976). The key to each of these early works was recognizing that the rate of mass-transport of substrate into the biofilm 
could limit system performance as much as the degradation potential by the bacteria inside the biofilm. Using straightforward $1 \mathrm{D}$ reaction + diffusion models, these early leaders showed how substrate concentrations decline with distance into the biofilm. The bacteria inside the biofilm often experience a much lower substrate concentration than those in the bulk liquid or at the outer surface of the biofilm.

Over four decades have passed since the work of the pioneers of biofilm modeling. Biofilm modeling has grown in scope, sophistication, and power. Wanner et al. (2006) published a comprehensive review of biofilm models, and the reader can find in it excellent details about the structure and use of biofilm models. Here, we provide a succinct overview of the key features of biofilm models.

\section{Components and processes}

A biofilm model is simply a set of mass-balance equations that are solved simultaneously. The core of a biofilm model involves defining the components and processes that are to be represented by the mass balances. The components are divided into two broad categories: the microorganisms and the materials that the microorganisms consume or produce. For modeling biofilms used in wastewater treatment, some important sets of components are:

- Heterotrophic bacteria that consume biochemical oxygen demand (BOD) and dissolved oxygen (DO)

- Nitrifying bacteria that consume ammonium $\left(\mathrm{NH}_{4}^{+}\right)$and DO, and produce nitrate $\left(\mathrm{NO}_{3}^{-}\right)$

- Denitrifying bacteria that consume $\mathrm{NO}_{3}^{-}$and BOD.

For the three sets of components, the microbiological processes are, respectively, aerobic oxidation of BOD, nitrification of $\mathrm{NH}_{4}^{+}$, and denitrification of $\mathrm{NO}_{3}^{-}$.

If we want to model all three processes, we need at least 7 mass balances: aerobic heterotrophs, nitrifying bacteria, denitrifying bacteria, $\mathrm{BOD}, \mathrm{DO}, \mathrm{NH}_{4}^{+}$, and $\mathrm{NO}_{3}^{-}$. The first three components are solids that form the biofilm. The last four components are soluble materials that can move through the biofilm. If we are only interested in aerobic removal of $\mathrm{BOD}$, the mass balance can be simplified to aerobic heterotrophs, BOD, and DO. If DO is not limiting, then the mass balances can be simplified further to heterotrophs and BOD.

While this 7-component, 3-process scenario is widely applicable, it is only one simple example of systems that can be represented by biofilm models. Other components and processes that can be incorporated into biofilm models include inert biomass, extracellular polymeric substances (EPS), refractory organic compounds, Anammox bacteria, sulfur-reducing and -oxidizing bacteria, and organic micro-pollutants.

In addition to microbiological processes, we must include mass-transport processes, because the substrates need to move from the bulk liquid to the microorganisms inside the biofilm. The mass-transport processes include diffusion or something that can be described by analogy to diffusion. They are driven by a concentration gradient, which explains why concentration gradients must develop in biofilms. Without a concentration gradient, the substrate cannot get to the bacteria inside the biofilm. Mass transport is important inside the biofilm and also for moving the substrates from the bulk liquid to the outside of the biofilm. The latter is called external mass transport, and it is controlled by the turbulence in the water moving past the biofilm, and the result is a concentration gradient between the bulk liquid and the outer surface of the biofilm.

Equations 1 and 2 give a simple example of steady-state mass balances for a single substrate inside a 1D biofilm. Equation 1 shows the balance of diffusion and microbial utilization inside the biofilm. Equation 2 shows how external mass transport provides the same flux of substrate from the bulk liquid as into the biofilm.

$0=D_{F} \frac{d^{2} S_{F}}{d z^{2}}-\frac{\hat{q} X_{F} S_{F}}{K+S_{F}}$

$J_{F}=\frac{D}{L_{L}}\left(S-S_{L F}\right)=\left.D_{F} \frac{d S_{F}}{d z}\right|_{z=0}$

$\mathrm{S}=$ substrate concentration in the bulk liquid, $\mathrm{S}_{\mathrm{LF}}=$ substrate concentration at the outer surface of the biofilm, $\mathrm{S}_{\mathrm{F}}=$ substrate concentration inside the biofilm, $\hat{q}=$ the maximum specific rate of substrate utilization, $\mathrm{K}=$ the half-maximumrate concentration, $\mathrm{X}_{\mathrm{F}}=$ concentration of active biomass in the biofilm, $\mathrm{D}_{\mathrm{F}}=$ substrate diffusion coefficient in the biofilm, $\mathrm{D}=$ substrate diffusion coefficient in the bulk liquid, $\mathrm{J}_{\mathrm{F}}=$ the substrate flux from the bulk liquid into the biofilm, $\mathrm{L}_{\mathrm{L}}=$ the mass transfer boundary layer thickness, and $\mathrm{z}=$ the distance dimension perpendicular to the biofilm surface. A detailed discussion of assumptions, boundary conditions, and solutions of Equations (1) and (2) is provided in the report by Wanner et al. (2006) or in related textbooks (Rittmann \& McCarty 200I; Morgenroth 2008).

Other important transport processes are the detachment of biomass from the biofilm and the attachment of suspended solids onto the biofilm. Detachment can be represented in several ways (Wanner et al. 2006), and it 
affects the total amount of metabolically active biomass that accumulates. If the detachment rate is slower than the net rate of biomass synthesis, the active biomass accumulates, or grows. A faster detachment rate causes the active biomass to shrink. Attachment of suspended solids also affects the total amount of biofilm and how much of it is active biomass versus non-active solids.

\section{Multi-dimensional models}

A very important feature of modern biofilm modeling is that the biofilm can also be represented in two or three dimensions, i.e., 2D and 3D models (Wanner et al. 2006). Modeling more than one dimension makes it possible to represent complex changes in the physical morphology of biofilms, as well as hydrodynamic interactions between the biofilm and the water flowing past the biofilm. Multi-dimensional models also allow more sophisticated treatment of complex ecological interactions that occur inside some biofilms. All of these features can be accentuated by recent developments using continuum as well as cellular-automaton and individual-biomass models, as well as movie-style visualization of the outputs.

While multi-dimensional models add a great deal of power to biofilm modeling and can offer exceptional insights into phenomena that occur in some settings, they demand heavy computing resources and deep programming expertise. Thus, 2D and 3D models are used today as research tools, but are not realistic for use by engineers to solve practical problems. Fortunately, a good 1D model can address all of the important questions that engineers need to address. This is true because the dominant processes in all biofilm settings are microbiological reaction and mass transport, which are captured well by a 1D model.

\section{One-dimensional models}

Wanner et al. 2006 give a comprehensive description of the types of 1D models available today. In brief, 1D models can be broken into three major types. Analytical models make simplifying assumptions so that Equation 1 can be solved with a closed-form analytical equation (Harremoes I976; Rittmann \& McCarty 200I). Examples of simplifying assumptions are using first-order or zero-order kinetics for the microbiological reaction and neglecting external masstransport resistance by assuming that $\mathrm{S}=\mathrm{S}_{\mathrm{LF}}$. Pseudoanalytical models involve algebraic approximations to the numerical solutions to Equations (1) and (2) (and sometimes also a mass balance on the biomass) (Rittmann \& McCarty
200I; Morgenroth 2008). They avoid the assumptions of analytical solutions and can be implemented with a simple spreadsheet for a limited number of components and processes (Wanner et al. 2006). Numerical models use computer techniques to solve the set of mass-balance equations. A convenient and often-used tool is AQUASIM (Wanner \& Morgenroth 2004; Wanner et al. 2006). Numerical solutions require the fewest simplifying assumptions and can be used to solve systems with many components and processes.

Although the following discussion of the GBRMP Framework focuses on using 1D numerical models, it is appropriate for any type of biofilm model.

\section{$\overline{\text { SELECTING A 1D MODEL }}$}

With limited understanding of biofilm processes, a novice modeler may be tempted to 'play it safe' by choosing the most complex biofilm model available. While this strategy might work out well for activated sludge modeling (Grau et al. 2009), it is not advisable for biofilm reactor modeling. One reason is that computing time often is a limiting factor for biofilm reactor modeling, and excess complexity increases the computational time by orders of magnitude. A second reason is that a complex biofilm model will require that the user provides many input parameters that are difficult to determine and for which no reliable default parameters have been defined. Choosing a too-complex model will incur many penalties for producing output that does not improve the usefulness for the user.

The following examples provide guidance for deciding what a suitable model complexity is. Figure 1 provides schematics of different modeling levels that correspond to the examples.

\section{Flux of the limiting substrate}

As an example, we consider the use of mathematical modeling to guide the design of a nitrifying moving-bed biofilm reactor. The reactor can be assumed to be completely mixed, and the target effluent ammonium concentrations is low. Based on some simple calculations (e.g., Morgenroth 2008) the engineer has determined that the biofilm will be limited by $\mathrm{NH}_{4}^{+}$and not by DO. Because this system is limited by a single substrate, a range of analytical, pseudoanalytical, and numerical biofilm models can be applied to calculate the $\mathrm{NH}_{4}^{+}$flux and, from that, the necessary surface area of biofilm carrier. If the design also requires the DO 


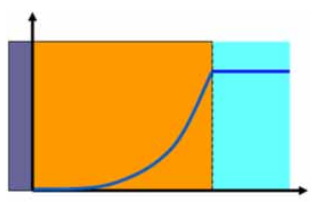

Level \#1: Mass transport limitation of single substrate considered

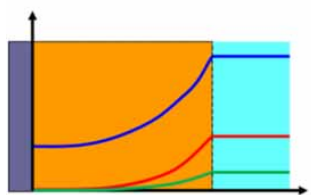

Level \#2: Mass transport limitations of multiple dissolved compounds considered

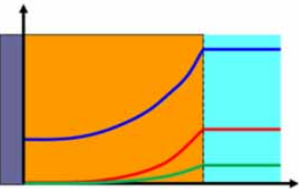

Level \#3: Mass transport limitations utilized to create ecological niches within the biofilm

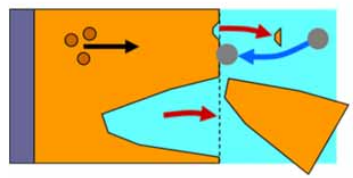

Level \#4: Mass transport of bacteria and particles, dynamic detachment and attachment considered

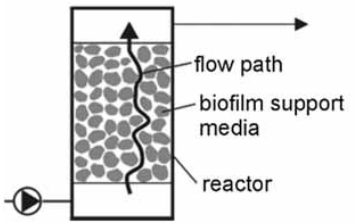

Level \#5: Linking biofilm processes with reactor configuration

Figure 1 | Five levels of increasingly complex biofilm models (Levels 1-4) and integrating modeling results in the overall system design (Level 5). Note that level of complexity for the modeling of levels \#2 and \#3 is identical; the difference is in the process objectives that in level \#3 considers the benefits resulting from mass transport limitations (e.g., different redox zones within the biofilm).

flux, it can be estimated from the $\mathrm{NH}_{4}^{+}$flux based on the known stoichiometry of $\mathrm{NH}_{4}^{+}$and $\mathrm{O}_{2}$ utilizations in nitrification (Level \#1 in Figure 1).

\section{Flux of the non-limiting substrate}

To design a nitrifying biofilter, the engineer wants to estimate $\mathrm{NH}_{4}^{+}$and DO fluxes into the biofilm along the length of the reactor. Due to the relatively high influent $\mathrm{NH}_{4}^{+}$concentration, it can be assumed that, in the front part of the biofilter, the reaction is DO-limited, whereas $\mathrm{NH}_{4}^{+}$is rate limiting towards the outlet of the filter. A $1 \mathrm{D}$ numerical model that takes into account dual substrate limitations would be appropriate. In addition, the model needs to take into account changes in the bulk phase concentrations along the length of the biofilter, such as by modeling several biofilm compartments in series (Level \#2 in Figure 1).

\section{Competition for substrate and space}

A biofilm reactor must oxidize dissolved organic carbon and $\mathrm{NH}_{4}^{+}$. Three soluble components need to be considered: organic substrate (represented as BOD or chemical oxygen demand (COD)), $\mathrm{NH}_{4}^{+}$, and their common electron acceptor, DO. Two unique groups of bacteria must be represented: faster growing heterotrophic bacteria oxidizing the organic substrate and slower growing autotrophic bacteria oxidizing $\mathrm{NH}_{4}^{+}$. Because performance depends on the relative penetration of the soluble substrates and also on the spatial distribution of the two groups of bacteria (Wanner \& Gujer I985), a mathematical model must explicitly represent the spatial distribution of all soluble substrates and biomass types. Many simulators, such as AQUASIM allow this level of detail (Wanner \& Morgenroth 2004; Boltz et al. 20Io). Depending on the type of reactor it may be suitable to assume a constant biofilm thickness or a constant detachment rate (Level \#2 in Figure 1).

\section{Beneficial use of partial penetration}

The engineer wants to predict the performance of an aerobic biofilm reactor in which mass transport limitations help to create unique local ecological niches: aerobic processes towards the outer surface and anoxic or anaerobic processes towards the core of the biofilm. A numerical model must be used to represent substrate transport and biomass distribution within the biofilm. The model needs to describe production and consumption of intermediates (e.g., $\mathrm{NO}_{3}^{-}$ and nitrite $\left.\left(\mathrm{NO}_{2}^{-}\right)\right)$and processes (e.g., denitrification) occurring inside the biofilm based on the intermediates. Thus, the biofilm must be sub-divided into sufficiently small numerical segments (or layers) to be able to represent different redox zones. Most commercial simulators allow for such representations (Level \#3 in Figure 1).

\section{Growth, detachment, and attachment}

The engineer wants to model the fate of soluble and particulate organic carbon in a moving-bed biofilm reactor. While the approach for modeling soluble substrate is well established (e.g., Equations (1) and (2)), how to describe the fate of particles within a biofilm reactor is uncertain. Attachment, detachment, and transport of particles depends on the biofilm's physical structure. Mechanisms of particle attachment, detachment, and hydrolysis have to be represented, despite uncertainty. Many biofilm reactor simulators include approaches to model particle attachment, but the lack of 
understanding of the actual mechanisms makes use of such built-in features risky. The modeler often must implement novel features based on the best understanding of the mechanisms affecting attachment and detachment (Level \#4 in Figure 1).

\section{Practical reactor implementation}

In some cases the performance of a biofilm reactor is not determined so much by substrate flux as by physical phenomena, such as mixing, clogging of the carrier in a biofilter, and carrier distribution in a moving-bed biofilm reactor. Mathematical modeling can help understand possible biological causes of some of these problems (e.g., too much biofilm accumulation), but many problems are more related to details of mechanical equipment or complex fluid dynamics. Such features sometimes cannot be represented by commercial simulators used for biofilm reactor modeling. In this case, the modeler has to acknowledge that a $1 \mathrm{D}$ biofilm model will not be sufficient to solve the problem (Level \#5 in Figure 1).

\section{GBRMP FRAMEWORK}

This section introduces a framework for the systematic step-bystep implementation and calibration of a mathematical model for a biofilm reactor (Figure 2). The framework was developed to describe biofilm reactors with suspended support media (e.g., the moving-bed biofilm reactor (MBBR) and integrated fixed-film activated sludge (IFAS)), but the underlying principles will be applicable to fixed-bed systems (e.g., biofilters and trickling filters) and to aerobic granular sludge systems. This framework is focused on basic principles, and it builds on experience from published reports on various aspects of biofilm reactor modeling: structured step-by-step approaches (Vigne et al. 2007; Vigne et al. 20I0; Barry et al. 20I2; Eldyasti et al. 20I2); colloidal organic matter (Albizuri et al. 2009; Albizuri et al. 20I4), laboratory-scale MBBRs (Vangsgaard et al. 20I3), predation (Revilla et al. 20I6), sensitivity and identifiability (Brockmann et al. 2008; Brockmann \& Morgenroth 2010; Boltz et al. 20I; Brockmann et al. 20I3), and experimental approaches to determine external mass-transfer resistance (Nogueira et al. 20I5).

\section{Step 1: obtain information on the biofilm reactor system}

Responsible application of a biofilm reactor model requires a good understanding of the actual biofilm reactor system to

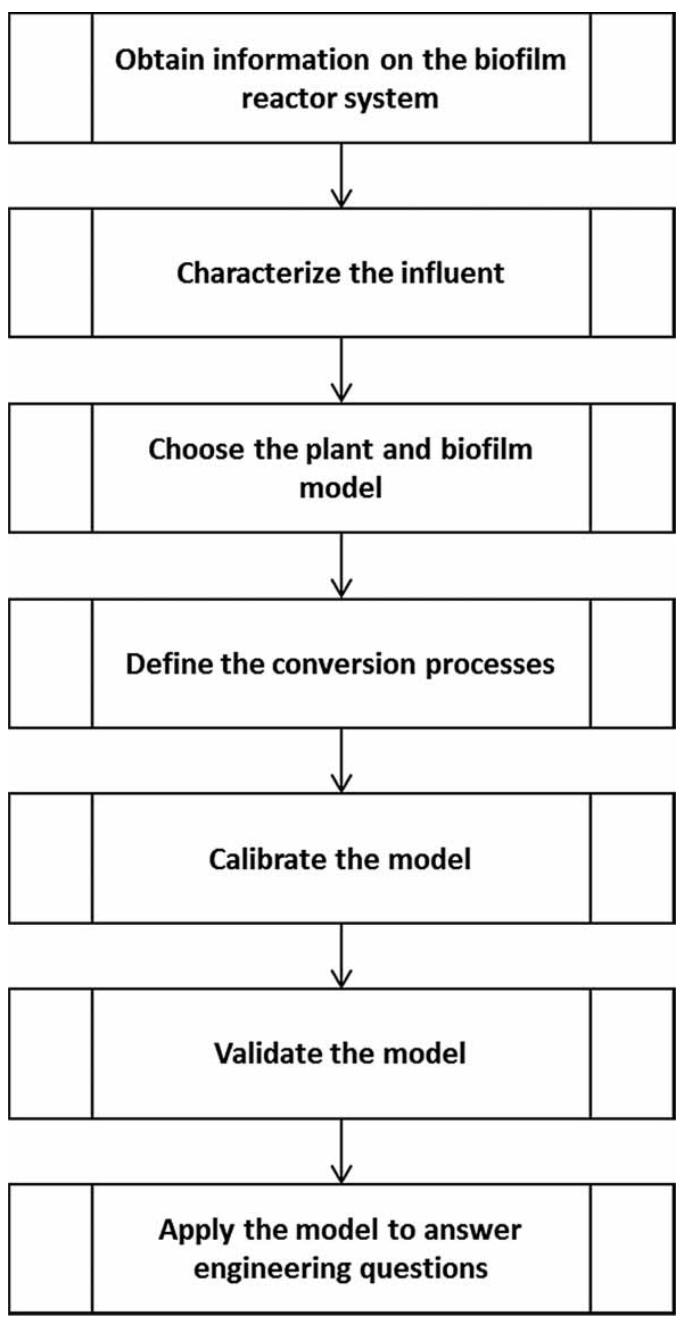

Figure 2 | Overall approach for Good Biofilm Reactor Modeling Practice.

be evaluated. This system-level understanding includes knowing reactor volumes, mixing conditions (water and biofilm media), available biofilm surface area $\left(A_{F}\right)$, microbial processes, oxygen transfer, and mechanisms and dynamics of detachment and biofilm thickness control (Table 1).

\section{Step 2: characterize the influent}

Wastewater flow and composition must be quantified in terms of average loadings, but also in terms of variability of flow and concentration of individual components (Table 1). In many cases, reactor performance will be impaired by varying loading. Biofilm reactors typically have a smaller hydraulic retention time compared to activated sludge systems and, therefore, have less hydraulic buffering and higher sensitivity to hydraulic variations. 
Table 1 | Recommended data requirements for GBRMP

\begin{tabular}{|c|c|c|}
\hline Plant and operational information & Wastewater characteristics & Reactor and biofilm information \\
\hline $\begin{array}{l}\text { - Flows (influent and recycles) } \\
\text { - Chemical dosing } \\
\text { - Water distribution into reactors } \\
\text { - Containment structure } \\
\text { - Aeration devices and control } \\
\text { - Mixing devices and control } \\
\text { - Hydrodynamic mixing conditions } \\
\text { - Carrier retention and water } \\
\text { collection systems }\end{array}$ & $\begin{array}{l}\text { - Wastewater composition (total and filtered } \mathrm{COD} \text {, } \\
\text { readily biodegradable COD }\left(\mathrm{S}_{\mathrm{B}}\right), \mathrm{NH}_{4}^{+}-\mathrm{N}, \mathrm{NO}_{2}^{-}-\mathrm{N} \text {, } \\
\left.\mathrm{NO}_{3}^{-}-\mathrm{N}, \mathrm{TKN} \text { or total nitrogen, } \mathrm{PO}_{4}^{3-}-\mathrm{P} \text {, total } \mathrm{P}\right) \text {, } \\
\text { VSS, TSS } \\
\text { - Internal recycle flow composition } \\
\text { - Daily and seasonal variability }\end{array}$ & $\begin{array}{l}\text { - MLSS and MLVSS of suspended biomass } \\
\text { - Amount of biofilm per carrier surface } \\
\quad\left(=\mathrm{X}_{\text {Tot,A }}\right) \\
\text { - Biofilm surface area }\left(\mathrm{A}_{\mathrm{F}}\right) \\
\text { - Biofilm thickness }\left(\mathrm{L}_{\mathrm{F}}\right) \text { and concentration } \\
\text { of biomass in the biofilm }\left(\mathrm{X}_{\mathrm{Tot}, \mathrm{F}}\right) \\
\text { - P-content of biomass } \\
\text { - SVI of suspended biomass } \\
\text { - Bulk liquid DO } \\
\text { - Temperature } \\
\text { - pH }\end{array}$ \\
\hline
\end{tabular}

In principle, wastewater composition can be characterized following procedures developed for activated sludge systems (Chapter 5.2 in Rieger et al. 20I3). While the chemical composition (e.g., COD) is independent of whether the wastewater is treated in an activated sludge or a biofilm system, the size characterization should reflect retention and degradation mechanisms (Corominas et al. 2010). In biofilm systems, soluble compounds are transported into the biofilm by diffusion, and the corresponding diffusion coefficient must be quantified. Colloidal and particulate components of COD must be evaluated to determine to what extent they are transported into the biofilm, attach to the biofilm, or pass through the system. Thus, the terms soluble, colloidal, and particulate refer, on the one hand, to particle size, but, on the other hand, also to removal mechanisms. Therefore, retention may be different for activated sludge and biofilm systems.

\section{Step 3: choose the plant and biofilm model}

Flow and retention of water streams, suspended particles and biomass, and biofilm carriers with biofilm have to be characterized and implemented in the mathematical model. Note that a reactor may be plug flow for the water stream and suspended particles, but completely mixed for biofilm carriers with biofilm in a specific stage or within the overall biofilm system (Rittmann 1982; Boltz et al. 20I7).

The biofilm itself is typically represented using a 1-D layered model (Wanner et al. 2006). For many applications, 3 to 10 layers are sufficient. Most commercially available simulators set the default number of layers to values between 3 and 10; thus, the user must be alert to increase the number of layers if needed. For thick and heterogeneous biofilms, more layers may be needed, but increasing the number of layers significantly increases computational time. The number of layers should be chosen based on an understanding of the biofilm thickness and the heterogeneity of process conditions within the biofilm. For example, if the aerobic zone towards the surface of the biofilm is on the order of $100 \mu \mathrm{m}$ thick, the thickness of a single layer must be $100 \mu \mathrm{m}$ or smaller. A rough rule of thumb is that the number of layers can be estimated by dividing the biofilm thickness by the thickness of the smallest process zone in the biofilm.

Biofilms are in many cases mass-transport limited, and model predictions are more sensitive to biofilm surface and external mass transfer resistance than to the overall amount of biomass. In that case, the modeler must either fix a certain biofilm thickness (e.g., based on measurements in the full-scale reactor) or have the model predict biofilm thickness (e.g., by fixing the value of the detachment and attachment rate coefficients). Detachment has a particularly strong influence on biofilm thickness and also on ecological niches for slow-growing microorganisms within the biofilm (Rittmann \& Manem 1992; Rittmann et al. 2002). Attachment of particulate and colloidal components also influences the availability of organic substrate within the biofilm and the seeding of the biofilm by suspended biomass. In addition to determining the average biofilm thickness, the modeler also must decide on considerations relating dynamic changes of biofilm thickness or biofilm detachment and decide on rate expressions for particle hydrolysis (Janning et al. 1998; Morgenroth et al. 2002; Hauduc et al. 2013). Biofilm detachment, attachment, and corresponding biofilm thickness (average or dynamically varying) can under some conditions have a significant influence on biofilm reactor performance in some circumstances, but are to-date still not well understood (Morgenroth \& Wilderer 2000; Morgenroth 2003). It is the responsibility of the 
model user to understand the implications of uncertainty in biofilm thickness or detachment modeling.

\section{Step 4: define the conversion processes}

Conversion processes in biofilm reactors - such as BOD and $\mathrm{NH}_{4}^{+}$oxidation or denitrification - are similar to processes in activated sludge. Therefore, the existing mathematical models developed for activated sludge systems (Henze 200o) can be adapted for biofilm reactors. A key difference between activated sludge and biofilm models is that biofilm models take mass transfer resistances explicitly into account, while, for activated sludge systems, the effect of mass transfer resistance into the floc typically is implicitly modeled by choosing a larger value of the half-maximumrate concentrations $\left(\mathrm{K}_{\mathrm{S}}\right)$. Thus, in biofilm reactor models, the value of the half-maximum-rate concentrations often are significantly smaller (e.g., $10 \%$ of the value in the activated sludge model) compared to default values in Henze (2000). When modeling IFAS systems, it will be necessary to use different values for half-maximum-rate concentrations for suspended biomass and for biomass in biofilms.

Different processes may be limiting in biofilm reactors compared to activated sludge processes. For example, biofilm reactors more commonly experience $\mathrm{NO}_{2}^{-}$accumulation compared to activated sludge systems; hence, it may be more important to implement a two-step nitrification model in a biofilm model, even if one-step nitrification works well for activated sludge.

\section{Step 5: calibrate the model}

Model calibration adjusts system-specific model parameters within reasonable ranges so that relevant model predictions match actual system performance. Ideally, a first comparison should be done for steady-state operation and model predictions. This is more likely in lab and pilot plants, where influent conditions and reactor operation can be kept constant for sufficiently long to approach steady state. Practical biofilm reactors almost always will have variability in the influent and often also in reactor operation. Achieving steady state in a biofilm simulation can be quite time consuming due to the many interactions among components and processes. A common mistake, used to save time, is to start with some random initial conditions and simply simulate for a few days. This mistake should be avoided, and simulations should be run until all components reach stable outputs. It can require several months of simulated time to reach steady state.
Because biofilm models are complex, model predictions often are non-linearly related to model input parameters. Furthermore, many of the model's output values are correlated for a range of modeling scenarios. While some model parameters (e.g., biofilm thickness) may have no influence on model predictions in certain situations (e.g., for thick biofilms and for low bulk phase substrate concentrations resulting in deep biofilms), the same parameter may have a dominant influence on model predictions in other settings (a thin biofilm with rapid external mass transport). Thus, parameter sensitivities are linked to initial values chosen (Brockmann et al. 2008). Regardless of this complexity, it is still possible to obtain relevant model predictions by following a structured approach and by taking into account parameter uncertainty when interpreting modeling results.

The calibration process should follow a hierarchy by which the most situation-specific parameters are adjusted first, while the most well-established parameters are maintained. For example, if the model is not producing results that correspond to the actual performance, the strategy for adjusting parameters should follow this sequence. First, the physical parameters - e.g., flow rates, volumes, and surface areas - should be double-checked. If that fails to fix the problem, the second step is to re-evaluate the influent characteristics. Third is to adjust biofilm parameters, such as biomass accumulation and external mass-transport boundary layer. Only if all of the preceding adjustments fail should the use resort to adjusting kinetic and, lastly, stoichiometric values.

Model calibration usually works best when performed sequentially following four steps: (1) biomass on carriers, (2) COD or BOD removal, (3) nitrogen removal, and (4) aeration. Figure 3 lays out a stepwise procedure for calibration. The following sub-sections describe typical procedures for each step of calibration.

\section{Calibrating biomass on carriers}

\section{Determine a realistic biofilm surface area for each reactor stage, and quantify the amount of biofilm biomass in the different reactor stages (calibration step 1a)}

In most cases, the supplier of the support media can provide the specific surface area for the medium (in $\mathrm{m}^{2}$ biofilm surface per $\mathrm{m}^{3}$ of reactor volume or per $\mathrm{m}^{3}$ of added media volume). Note that this specific surface area can depend on reactor operation; under certain conditions, the actual value is actually larger than reported by the manufacturer (e.g., due to the formation of streamers on the biofilm that increase the available surface area) or smaller than reported 


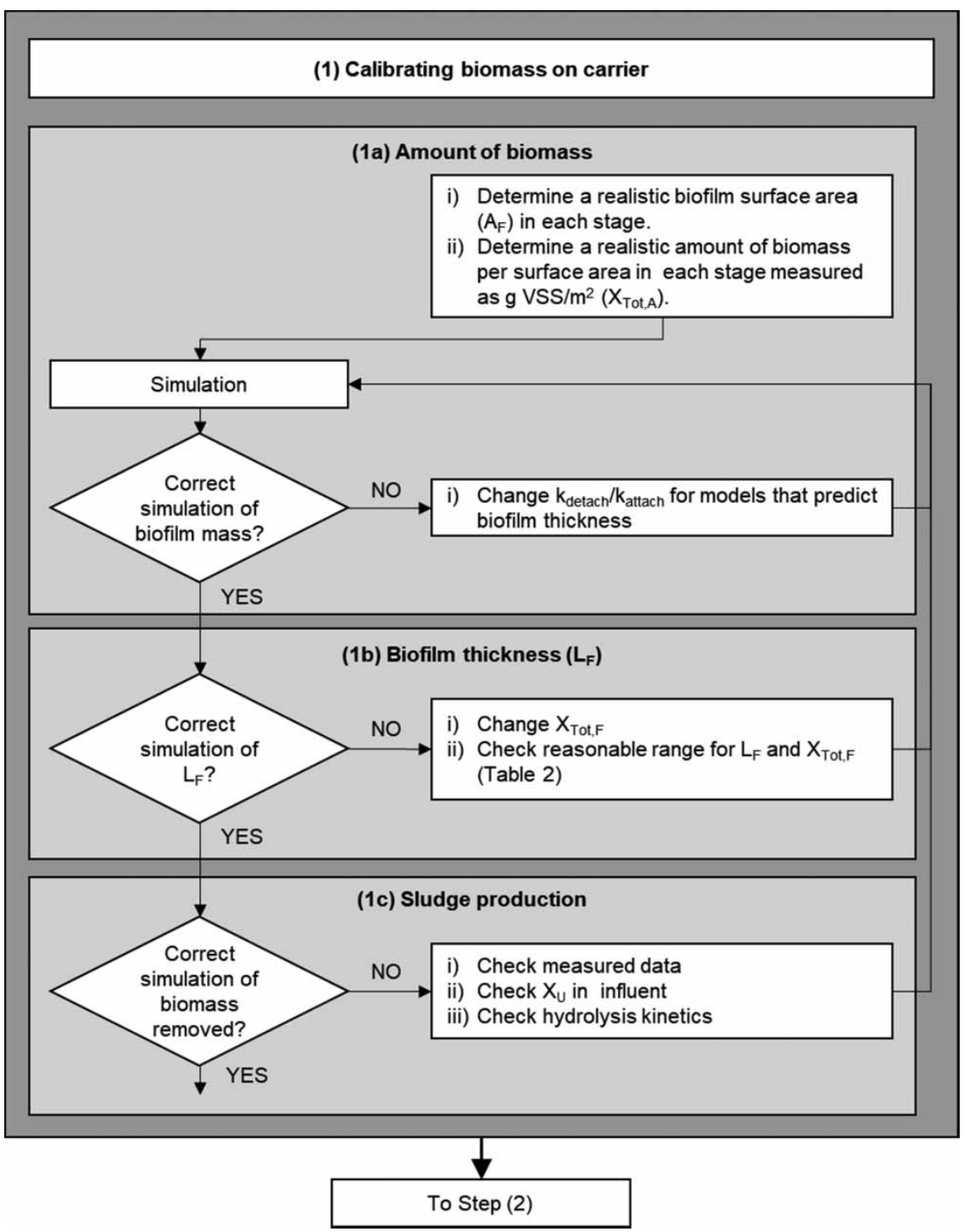

Figure 3 Stepwise calibration of a biofilm reactor model. Calibration should follow this general sequence, but ultimately may need additional cycling through the calibration steps. (continued)

by the manufacturer (e.g., if pores or a heterogeneous surface of the support media are fully overgrown by biofilm). The actual available specific surface area may change with influent substrate loading, between winter and summer, from startup to long-term operation, due to predation, or due to changes in mechanical forces (e.g., through changes in the fill ratio or aeration intensity).

For an operating biofilm plant, the amount of biofilm biomass can be measured by sampling a known amount of media from different stages and measuring VSS (APHA, 2012). Based on the VSS per removed carrier and the specific surface area of the carrier, the amount of biomass per surface area $\left(A_{F}\right)$ can be calculated. The measured amount of biomass should then be compared to model predictions. The model can be calibrated to match the observed biomass by adjusting detachment and/or attachment coefficients (if the biofilm thickness is predicted by the model) or by adjusting the biofilm thickness $\left(\mathrm{L}_{\mathrm{F}}\right)$ or the concentration of biomass in the biofilm $\left(\mathrm{X}_{\mathrm{Tot}, \mathrm{F}}\right)$ (if the biofilm thickness is fixed) (see also next step).

\section{Biofilm thickness (calibration step 1b)}

Once the biomass per surface area $\left(=\mathrm{X}_{\mathrm{Tot}, \mathrm{A}}=\mathrm{X}_{\mathrm{Tot}, \mathrm{F}} \cdot \mathrm{L}_{\mathrm{F}}\right)$ is fixed, then the combination of biofilm thickness $\left(\mathrm{L}_{\mathrm{F}}\right)$ and biomass concentration $\left(\mathrm{X}_{\mathrm{Tot}, \mathrm{F}}\right)$ must be chosen to match 


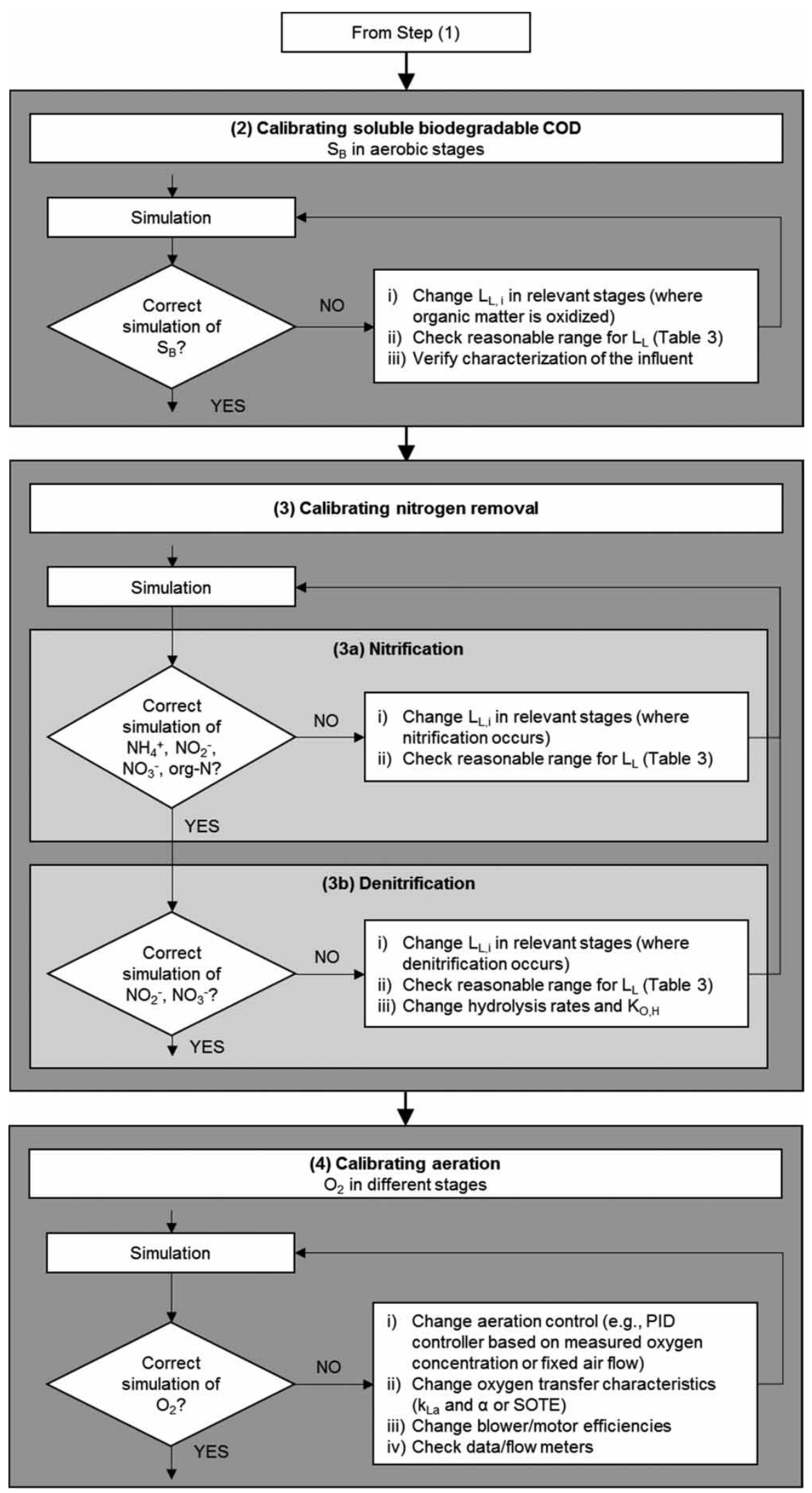

Figure 3 | Continued. 
this value. Ideally the biofilm thickness should be measured for the actual biofilm reactor (e.g., microscopically after sampling a number of carriers, e.g., Bakke \& Olsson I986). Once the biofilm thickness has been determined, the value of $\mathrm{X}_{\mathrm{Tot}, \mathrm{F}}$ can be directly calculated. For the biofilm thickness and the biomass concentration, typical values are provided in Table 2.

\section{Sludge production (calibration step 1c)}

Sludge production in the actual treatment plant and in model predictions should be compared. Large deviations may mean that sludge production in the treatment plant was measured incorrectly, particularly since biomass detachment from the biofilm carriers is a dynamic process requiring long-term sampling to achieve representative values. Another source of deviations between modeling results and observed reactor operation is an error in the wastewater characterization (e.g., inert particulate organic matter) or neglecting $S_{B}$ in the effluent. COD mass balancing and evaluation of oxygen input (aeration) can be used to verify the measured sludge production (Rieger et al. 20I3).

\section{COD removal}

\section{Degradation of soluble biodegradable COD (calibration step 2)}

The dominant parameter influencing the degradation of soluble biodegradable organic substrate $\left(\mathrm{S}_{\mathrm{B}}\right)$ is the mass transfer boundary layer thickness $\left(\mathrm{L}_{\mathrm{L}}\right)$, if biofilm thickness and concentration of biomass in the biofilm are fixed. Therefore, measured bulk phase $S_{B}$ concentrations are compared with model predictions and calibrated by adjusting $L_{L}$. Typical values for $L_{L}$ are provided in Table 3. Note that $\mathrm{S}_{\mathrm{B}}$ should not be confused with the soluble $\mathrm{COD}$ measured in the reactor, as the soluble COD also includes the non-biodegradable soluble COD. In activated sludge modeling, particle characteristics (e.g., size) influence retention in a clarifier. In modeling a biofilm reactor, particle characteristics also influence attachment, retention, and potentially transport into the biofilm. Experimental procedures are available to differentiate between soluble, colloidal, and particulate COD (e.g., by measuring the filtered COD before or after flocculation. For details of wastewater characterization and an overview of related methods see Rieger et al. (2013).

Note, as biofilm thickness and structure and mixing due to aeration may vary for different reactor stages, the value of
$\mathrm{L}_{\mathrm{L}}$ can be significantly different for the different stages. As $\mathrm{L}_{\mathrm{L}}$ is influenced by aeration intensity, the value of $\mathrm{L}_{\mathrm{L}}$ will also change within a given stage for different air flow rates. One factor that can influence organic substrate degradation is the bulk-phase oxygen concentration, which should be measured and included. Another factor influencing organic substrate degradation is suspended heterotrophic biomass (e.g., from detached biomass). Even without selective retention of suspended biomass in the system, the effect of suspended biomass can be significant and should be considered experimentally (e.g., by measuring the removal rate of biofilm carriers after removing bulk phase biomass) and in the mathematical model.

\section{Nitrogen removal}

\section{Nitrification (calibration step 3a)}

Nitrification is significantly affected by the presence of heterotrophic growth (Wanner \& Gujer 1985), which means that model predictions of nitrification can be realistic only if degradation of organic carbon and growth of heterotrophic bacteria are modeled correctly (Step 2). Nitrification in the actual plant should be evaluated based on measurements of organic nitrogen, $\mathrm{NH}_{4}^{+}, \mathrm{NO}_{2}^{-}$, and $\mathrm{NO}_{3}^{-}$. In many practical cases, only $\mathrm{NH}_{4}^{+}$and $\mathrm{NO}_{3}^{-}$are measured, resulting in significant uncertainty in quantifying the actual extent of nitrification. Measured nitrification rates and nitrogen compounds can be compared with model predictions and, like in Step 2, the rate of ammonia oxidation can be adjusted by adjusting the value of $\mathrm{L}_{\mathrm{L}}$ in the appropriate stages.

Potential pitfalls that should be considered when modeling nitrification are:

- Ammonification of organic nitrogen may be limited in biofilm reactors due to low HRT.

- Nitrification may be limited by low pH (models usually monitor alkalinity as proxy for $\mathrm{pH}$ ), low phosphorus concentrations, or by the presence of inhibitory compounds (check for these limitations both in the model and in the real plant).

- The number of layers in the mathematical model may have a significant influence on model predictions as it influences how competition between heterotrophic and autotrophic bacteria is modelled.

If in doubt, it may be worth the effort to sample biofilm carriers and measure nitrification and oxygen uptake rates in batch experiments after adding ammonium (no organic carbon) under different operating conditions (variation of 
Table 2 | Reasonable parameter values for the concentration of biomass in the biofilm, biofilm thickness, and oxygen transfer to serve as a plausibility check for measured or calibrated values

\begin{tabular}{|c|c|c|c|c|c|}
\hline & & Carbon oxidation & Nitrification & $\begin{array}{l}\text { Tertiary denitrification with } \\
\text { methanol }\end{array}$ & $\begin{array}{l}\text { Denitrification on } \\
\text { membrane with } \mathrm{H}_{2}\end{array}$ \\
\hline \multicolumn{2}{|c|}{$\begin{array}{l}\text { Concentration of biomass in the biofilm }\left(\mathrm{X}_{\mathrm{Tot}, \mathrm{F}}\right), \mathrm{g} \\
\text { VSS/L of biofilm }\end{array}$} & $20-30$ & $40-60$ & $40-60$ & $40-60$ \\
\hline \multirow[t]{8}{*}{$\begin{array}{l}\text { Biofilm thickness } \\
\quad\left(\mathrm{L}_{\mathrm{F}}\right), \mu \mathrm{m}\end{array}$} & Trickling filter & $\begin{array}{l}500 \text { (Top of trickling filter) } \\
100 \text { (Low loaded bottom) }\end{array}$ & $\begin{array}{l}\text { 100-200 } \\
\quad \text { (Top of trickling filter) } \\
20-40 \text { (Low loaded bottom) }\end{array}$ & $\begin{array}{l}\text { Like for carbon oxidation, } \\
\text { but perhaps with } \\
\text { streamers }\end{array}$ & \\
\hline & $\mathrm{RBC}$ & $\begin{array}{l}500 \text { (First section) } \\
100 \text { (Low loaded last } \\
\text { section) }\end{array}$ & $\begin{array}{l}\text { 100-200 (First section) } \\
\text { 20-40 (Low loaded last } \\
\text { section) }\end{array}$ & & \\
\hline & BAF (dense media) & $\begin{array}{l}100 \text { (before backwashing) } \\
40-60 \text { (after backwashing) }\end{array}$ & $20-40$ & & \\
\hline & BAF (floating media) & $100-200$ & $80-120$ & & \\
\hline & MBBR & 500 & $100-200$ & & \\
\hline & $\begin{array}{l}\text { MBfR (membrane attached } \\
\text { biofilm reactor) }\end{array}$ & & & - & $20-80$ \\
\hline & $\begin{array}{l}\text { Continuous washed sand filter } \\
\text { (Dynasand) }\end{array}$ & & & $\begin{array}{l}10-20 \\
\quad \text { No streamers }\end{array}$ & \\
\hline & Fluidized bed reactors & & $10-20$ & $40-50$ & \\
\hline \multicolumn{2}{|l|}{$\mathbf{D}_{\mathbf{F}}$} & $=0.8 \cdot \mathrm{D}$ & & & \\
\hline \multirow{3}{*}{$\begin{array}{l}\text { Oxygen transfer } \\
\text { efficiency: } \alpha\end{array}$} & BAF & 1 & & & \\
\hline & MBBR & $0.5-0.9$ & & & \\
\hline & IFAS & Like for activated sludge, but & dia may influence the value & & \\
\hline
\end{tabular}


Table 3 Typical parameter values for flow, carrier sizes, and the external mass transfer boundary layer thickness $\left(L_{L}\right)$ to serve as a plausibility check for measured or calibrated values

\begin{tabular}{|c|c|c|c|}
\hline Type of reactor & Liquid velocity in $\mathrm{m} / \mathrm{h}$ & Carrier size in $\mathbf{~ m m}$ & $\mathbf{L}_{\mathbf{L}}$ in $\mu \mathrm{m}$ \\
\hline Slow sand filter & 0.04 & 0.6 & 100 \\
\hline Rapid sand filter & 5 & 0.7 & 20 \\
\hline Trickling filter (low rate) & 0.08 & 40 & 1,500 \\
\hline Trickling filter (high rate) & 1.7 & 40 & 20 \\
\hline Submerged biofilm reactor & $2-10$ & $2-6$ & 100 \\
\hline MBBR & a & $\mathrm{b}$ & $50-180$ \\
\hline UASB reactor & 1 & 3 & 200 \\
\hline Fluidized bed & 33 & 1 & 20 \\
\hline
\end{tabular}

${ }^{\text {a }}$ not applicable, ${ }^{b}$ variable geometries as described in McQuarrie \& Boltz (2011), Sources: Kissel (1986), Morgenroth (2008).

File: GBRMP_FrameworkBiofilmReactors.Rev_01f_toWST.21nov17.docx, 05.01.2018 16:55.

oxygen set point and/or mixing intensity) to clearly identify what is limiting nitrification. Other comments regarding the calibration of $\mathrm{L}_{\mathrm{L}}$ from Step 2 (above), such as the influence of air flow rates on $\mathrm{L}_{\mathrm{L}}$, should be considered.

\section{Denitrification (calibration step 3 b)}

Realistic calibration of denitrification relies on reliable measurements of all nitrogen species, including $\mathrm{NO}_{3}^{-}, \mathrm{NO}_{2}^{-}$, $\mathrm{NH}_{4}^{+}$, and organic nitrogen (in particulate organic matter and from biomass synthesis). Modeled denitrification rates depend on a range of different factors that need to be adjusted based on understanding of the actual reactor system:

- Availability of competing electron acceptors (e.g., DO).

- Availability of soluble organic carbon $\left(\mathrm{S}_{\mathrm{B}}\right)$ or storage products (e.g., PHA) as electron donor and hydrolysis of colloidal or particulate organic carbon in the stage where denitrification occurs.

- External boundary layer thickness $\left(\mathrm{L}_{\mathrm{L}}\right)$ in the stage where denitrification occurs. Again, note that the value of $\mathrm{L}_{\mathrm{L}}$ in this stage will most likely be larger compared to reactors with more mixing due to intensive aeration.

- As for nitrification, choosing the right number of layers for the model is crucial for modeling simultaneous nitrification and denitrification.

\section{Aeration}

Modeling aeration, gas transfer, and oxygen transfer between stages (calibration step 4)

Biofilm reactors usually are mass-transfer limited, and oxygen often is the limiting factor for carbon oxidation and nitrification, and can inhibit denitrification. Therefore, overall model predictions will be very sensitive to correctly modeling the availability of oxygen. Different approaches are available. If a particular stage in the real plant is operated with a set point for bulk-phase oxygen, then such a fixed bulk phase concentration should also be implemented in the model. For reactors without aeration the bulk phase oxygen concentration should not simply be set to zero as oxygen may enter from recycles from other reactors in addition to transfer from the atmosphere. Thus, bulk-phase oxygen concentrations should always be modeled as a state variable rather than simply assuming a fixed value.

As noted in the previous calibration steps, air flow influences mixing intensity and indirectly the values of $\mathrm{L}_{\mathrm{L}}$ in the different stages. That means that it would be desirable to develop an empirical correlation between oxygen transfer and gas flow (i.e., $\mathrm{k}_{\mathrm{L}} \mathrm{a}$ and $\alpha$ values) and, in addition, to also develop an empirical correlation between the gas flow and $\mathrm{L}_{\mathrm{L}}$.

\section{Some typical pitfalls and suggestions}

- Reactor hydraulics of full-scale plants in general are quite different from pilot plants or from the original design assumptions made, e.g., an assumed completely mixed reactor may in reality be semi-plug flow.

- The model utilized might not be applicable to the problem: e.g., biological phosphorus removal is taking place in the bulk phase of an IFAS, which requires that ASM2d be used for this aspect.

- The calibration steps outlined above do not always proceed in a linear manner. For example, calibration of aeration processes may affect earlier steps that involve DO limitation. Therefore, the entire process may need to proceed in an iterative manner. 


\section{CONCLUSIONS AND SUMMARY}

A wide range of biofilm models and modeling platforms are available. A researcher or practitioner can take advantage of biofilm modeling to gain insight into what controls the performance of a process and for optimizing performance. A critical first step is choosing a model that has the appropriate level of complexity in terms of components and dimensionality. A good strategy is to choose the simplest model that includes the needed components. In most cases, a 1D biofilm model will work best, and good choices are available for doing 1D modeling. They can range from hand-calculation analytical solutions, simple spreadsheets, and numerical-method platforms.

We present a 5-step framework for good practice in biofilm reactor modeling (GBRMP). The first four steps are: (1) Obtain information on the biofilm reactor system, (2) Characterize the influent, (3) Choose the plant and biofilm model, and (4) Define the conversion processes. Each of these steps demands that the model user understands the most important components and features of the system. Establishing this kind of disciplined thinking is one of the main benefits of doing biofilm modeling.

The fifth step is to calibrate the model: System-specific model parameters are adjusted within reasonable ranges so that model outputs match actual system performance. Calibration is not a simple 'by the numbers' process, and it requires that the modeler follows a logical hierarchy of steps. Calibration requires that the modeler uses sound judgment about which parameters are system-specific and open to calibration. It also requires that the adjusted parameters remain within realistic bounds and that the calibration process be carried out in an iterative manner.

Once each of steps 1 through 5 is completed satisfactorily, the calibrated model, after some validation, can be used for its intended purpose, such as optimizing performance, trouble-shooting poor performance, or gaining deeper understanding of what controls process performance.

\section{ACKNOWLEDGEMENTS}

The authors acknowledge financial support offered by World Water Works and the support of their Chief Technology Officer Mr. Chandler Johnson. We also acknowledge the support of Kruger, North America. Peter Vanrolleghem holds the Canada Research Chair in Water Quality Modelling.

\section{$\overline{\text { REFERENCES }}$}

Albizuri, J., van Loosdrecht, M. C. M. \& Larrea, L. 2009 Extended mixed-culture biofilms (MCB) model to describe integrated fixed film/activated sludge (IFAS) process behaviour. Water Science and Technology 60 (12), 3233-3241.

Albizuri, J., Grau, P., Christensson, M. \& Larrea, L. 2014 Validating the colloid model to optimise the design and operation of both moving-bed biofilm reactor and integrated fixed-film activated sludge systems. Water Science and Technology 69 (7), 1552-1557.

Atkinson, B. \& Davies, I. J. 1974 The overall rate of substrate uptake (reaction) by microbial films. Part I - A biological rate equation. Trans.Inst.Chem.Engrs. 52, 248-259.

Bakke, R. \& Olsson, P. Q. 1986 Biofilm thickness measurements by light microscopy. Journal of Microbiological Methods $\mathbf{5}$, 93-98.

Barry, U., Choubert, J. M., Canler, J. P., Heduit, A., Robin, L. \& Lessard, P. 2012 A calibration protocol of a one-dimensional moving bed bioreactor (MBBR) dynamic model for nitrogen removal. Water Science and Technology 65 (7), 1172-1178.

Boltz, J. P. \& Daigger, G. T. 2oIo Uncertainty in bulk-liquid hydrodynamics and biofilm dynamics creates uncertainties in biofilm reactor design. Water Science and Technology 61 (2), 307-316.

Boltz, J. P., Morgenroth, E. \& Sen, D. 2010 Mathematical modelling of biofilms and biofilm reactors for engineering design. Water Science and Technology 62 (8), 1821-1836.

Boltz, J. P., Morgenroth, E., Brockmann, D., Bott, C., Gellner, W. J. \& Vanrolleghem, P. A. 20II Systematic evaluation of biofilm models for engineering practice: components and critical assumptions. Water Science and Technology 64 (4), 930-944.

Boltz, J. P., Johnson, B. R., Takacs, I., Daigger, G. T., Morgenroth, E., Brockmann, D., Kovacs, R., Calhoun, J. M., Choubert, J. M. \& Derlon, N. 2017 Biofilm carrier migration model describes reactor performance. Water Sci Technol 75 (12), 2818-2828.

Brockmann, D. \& Morgenroth, E. 2oIo Evaluating operating conditions for outcompeting nitrite oxidizers and maintaining partial nitrification in biofilm systems using biofilm modeling and Monte Carlo filtering. Water Research 44 (6), 1995-2009.

Brockmann, D., Rosenwinkel, K. H. \& Morgenroth, E. 2008 Practical identifiability of biokinetic parameters of a model describing two-step nitrification in biofilms. Biotechnology and Bioengineering 101 (3), 497-514.

Brockmann, D., Caylet, A., Escudie, R., Steyer, J. P. \& Bernet, N. 2013 Biofilm model calibration and microbial diversity study using Monte Carlo simulations. Biotechnology and Bioengineering 110 (5), 1323-1332.

Corominas, L., Rieger, L., Takacs, I., Ekama, G., Hauduc, H., Vanrolleghem, P. A., Oehmen, A., Gernaey, K. V., van Loosdrecht, M. C. M. \& Comeau, Y. 2010 New framework for 
standardized notation in wastewater treatment modelling. Water Science and Technology 61 (4), 841-857.

Daigger, G. T. 20II A practitioner's perspective on the uses and future developments for wastewater treatment modelling. Water Science and Technology 63 (3), 516-526.

Eldyasti, A., Nakhla, G. \& Zhu, J. 2012 Development of a calibration protocol and identification of the most sensitive parameters for the particulate biofilm models used in biological wastewater treatment. Bioresource Technology 111, 111-121.

Grau, P., Copp, J., Vanrolleghem, P. A., Takacs, I. \& Ayesa, E. 2009 A comparative analysis of different approaches for integrated WWTP modelling. Water Science and Technology 59 (1), 141-147.

Harremoes, P. I976 The significance of pore diffusion to filter denitrification. Journal Water Pollution Control Federation 48 (2), 377-388.

Hauduc, H., Rieger, L., Oehmen, A., van Loosdrecht, M. C. M., Comeau, Y., Heduit, A., Vanrolleghem, P. A. \& Gillot, S. 2013 Critical review of activated sludge modeling: state of process knowledge, modeling concepts, and limitations.

Biotechnology and Bioengineering 110 (1), 24-46.

Henze, M. 2000 The Activated Sludge Models (1, 2, 2d, and 3). IWA Scientific \& Technical Report. IWA Publishing, London, UK

Henze, M., Grady Jr., C. P. L., Gujer, W., Marais, G. v.R. \& Matsuo, T. Ig87 Activated Sludge Model No. 1. IAWPRC, London.

Janning, K. F., Le Tallec, X. \& Harremoes, P. 1998 Hydrolysis of organic wastewater particles in laboratory scale and pilot scale biofilm reactors under anoxic and aerobic conditions. Water Science and Technology 38 (8-9), 179-188.

Kissel, J. C. 1986 Modeling mass-transfer in biological waste-water treatment processes. Water Science and Technology 18 (6), 35-45.

McQuarrie, J. P. \& Boltz, J. P. 20II Moving Bed biofilm reactor technology: process applications, design, and performance. Water Environment Research 83 (6), 560-575.

Morgenroth, E. 2003 Detachment - an often overlooked phenomenon in biofilm research and modeling. In: Biofilms in Wastewater Treatment (S. Wuertz, P. A. Wilderer \& P. L. Bishop, eds). IWA Publishing, pp. 264-290.

Morgenroth, E. 2008 Modelling Biofilms. In: Biological Wastewater Treatment - Principles, Modelling, and Design (M. Henze, M. C. M. van Loosdrecht, G. Ekama \& D. Brdjanovic, eds). IWA Publishing, London.

Morgenroth, E. \& Wilderer, P. A. 2000 Influence of detachment mechanisms on competition in biofilms. Water Research 34 (2), 417-426.

Morgenroth, E., Kommedal, R. \& Harremoes, P. 2002 Processes and modeling of hydrolysis of particulate organic matter in aerobic wastewater treatment - A review. Water Science and Technology 45 (6), 25-40.

Nogueira, B. L., Perez, J., van Loosdrecht, M. C. M., Secchi, A. R., Dezotti, M. \& Biscaia, E. C. 20I5 Determination of the external mass transfer coefficient and influence of mixing intensity in moving bed biofilm reactors for wastewater treatment. Water Research 80, 90-98.

Revilla, M., Galan, B. \& Viguri, J. R. 2016 An integrated mathematical model for chemical oxygen demand (COD) removal in moving bed biofilm reactors (MBBR) including predation and hydrolysis. Water Research 98, 84-97.

Rieger, L., Gillot, S., Langergraber, G., Ohtsuki, T., Shaw, A., Takacs, I. \& Winkler, S. 2013 Guidelines for Using Activated Sludge Models. IWA Publishing.

Rittmann, B. E. 1982 Comparative performance of biofilm reactor types. Biotechnology and Bioengineering 24, 1341-1370.

Rittmann, B. E. \& Manem, J. A. 1992 Development and experimental evaluation of a steady-State, multispecies biofilm model. Biotechnology and Bioengineering 39 (9), 914-922.

Rittmann, B. E. \& McCarty, P. L. 200 Environmental Biotechnology: Principles and Applications. McGraw-Hill, New York.

Rittmann, B. E., Stilwell, D. \& Ohashi, A. 2002 The transient-state, multiple-species biofilm model for biofiltration processes. Water Research 36 (9), 2342-2356.

Vangsgaard, A. K., Mutlu, A. G., Gernaey, K. V., Smets, B. F. \& Sin, G. 2013 Calibration and validation of a model describing complete autotrophic nitrogen removal in a granular SBR system. Journal Of Chemical Technology And Biotechnology doi: $10.1002 /$ jctb.4060.

Vigne, E., Choubert, J. M., Canler, J. P., Heduit, A. \& Lessard, P. 2007 Toward an operational dynamic model for tertiary nitrification by submerged biofiltration. Water Science and Technology 55 (8-9), 301-308.

Vigne, E., Choubert, J. M., Canler, J. P., Heduit, A., Sorensen, K. \& Lessard, P. 20I0 A biofiltration model for tertiary nitrification of municipal wastewaters. Water Research 44 (15), 4399-4410.

Wanner, O. \& Gujer, W. 1985 Competition in biofilms. Water Science and Technology 17 (2-3), 27-44.

Wanner, O. \& Morgenroth, E. 2004 Biofilm modeling with AQUASIM. Water Science and Technology 49 (11-12), 137-144.

Wanner, O., Eberl, H. J., Morgenroth, E., Noguera, D. R., Picioreanu, C., Rittmann, B. E. \& van Loosdrecht, M. C. M. 2006 Mathematical Modeling of Biofilms. IWA Publishing, London, UK.

Williamson, K. \& McCarty, P. L. 1976 Verification studies of the biofilm model for bacterial substrate utilization. Journal Water Pollution Control Federation 48 (2), 281-296.

First received 9 January 2017; accepted in revised form 16 December 2017. Available online 16 January 2018 